\title{
BMJ Open Neighbourhood walkability, daily steps and utilitarian walking in Canadian adults
}

\author{
Samantha Hajna, ${ }^{1}$ Nancy A Ross, ${ }^{1,2}$ Lawrence Joseph, ${ }^{1,2}$ Sam Harper, ${ }^{1}$ \\ Kaberi Dasgupta ${ }^{1,3}$
}

To cite: Hajna S, Ross NA, Joseph L, et al. Neighbourhood walkability, daily steps and utilitarian walking in Canadian adults. BMJ Open 2015;5:e008964. doi:10.1136/bmjopen-2015008964

- Prepublication history and additional material is available. To view please visit the journal (http://dx.doi.org/ 10.1136/bmjopen-2015008964)

Received 2 June 2015 Revised 31 August 2015 Accepted 28 September 2015

\section{E CrossMark}

${ }^{1}$ Department of Epidemiology, Biostatistics and Occupational Health, McGill University, Montréal, QC, Canada

${ }^{2}$ Department of Geography, McGill University, Montréal, QC, Canada

${ }^{3}$ Division of Clinical Epidemiology, Department of Medicine, McGill University Health Centre, Montréal, QC, Canada

Correspondence to Dr Kaberi Dasgupta; kaberi.dasgupta@mcgill.ca

\section{ABSTRACT}

Objectives: To estimate the associations of neighbourhood walkability (based on Geographic Information System (GIS)-derived measures of street connectivity, land use mix, and population density and the Walk Score) with self-reported utilitarian walking and accelerometer-assessed daily steps in Canadian adults.

Design: A cross-sectional analysis of data collected as part of the Canadian Health Measures Survey (20072009).

Setting: Home neighbourhoods (500 m polygonal street network buffers around the centroid of the participant's postal code) located in Atlantic Canada, Québec, Ontario, the Prairies and British Columbia. Participants: 5605 individuals participated in the survey. 3727 adults ( $\geq 18$ years) completed a computer-assisted interview and attended a mobile clinic assessment. Analyses were based on those who had complete exposure, outcome and covariate data $(\mathrm{n}=2949)$.

Main exposure measures: GIS-derived walkability (based on land use mix, street connectivity and population density); Walk Score.

Main outcome measures: Self-reported utilitarian walking; accelerometer-assessed daily steps.

Results: No important relationship was observed between neighbourhood walkability and daily steps. Participants who reported more utilitarian walking, however, accumulated more steps ( $<1$ h/week: 6613 steps/day, $95 \% \mathrm{Cl} 6251$ to $6975 ; 1$ to $5 \mathrm{~h} /$ week: 6768 steps/day, $95 \% \mathrm{Cl} 6420$ to $7117 ; \geq 6$ h/week: 7391 steps/day, $95 \% \mathrm{Cl} 6972$ to 7811$)$. There was a positive graded association between walkability and odds of walking $\geq 1 \mathrm{~h} /$ week for utilitarian purposes (eg, Q4 vs Q1 of GIS-derived walkability: $\mathrm{OR}=1.66,95 \% \mathrm{Cl} 1.31$ to 2.11 ; $Q 3$ vs $Q 1$ : $O R=1.41,95 \% \mathrm{Cl} 1.14$ to 1.76 ; $Q 2$ vs Q1: $\mathrm{OR}=1.13,95 \% \mathrm{Cl} 0.91$ to 1.39 ) independent of age, sex, body mass index, married/common law status, annual household income, having children in the household, immigrant status, mood disorder, perceived health, ever smoker and season.

Conclusions: Contrary to expectations, living in more walkable Canadian neighbourhoods was not associated with more total walking. Utilitarian walking and daily steps were, however, correlated and walkability demonstrated a positive graded relationship with utilitarian walking.

\section{Strengths and limitations of this study}

- This is the first study to estimate the relationship of Geographic Information Systems-derived measures of neighbourhood walkability (ie, street connectivity, land use mix and population density), and the Walk Score with both selfreported utilitarian walking and accelerometerassessed daily steps in a large sample of Canadian adults.

- Major strengths of this study included a large sample size, assessment of daily steps using accelerometers, consideration of individual and area-level covariates, use of multiple measures of walkability, and the inclusion of a wide variety of neighbourhoods from across Canada.

- Owing to the cross-sectional study design, conclusions regarding causality and the directionality of the associations could not be made.

- The amounts of self-reported utilitarian walking and daily steps that occurred in the home neighbourhood were unknown. Studies on the association between neighbourhood walkability and neighbourhood-specific physical activity are needed.

\section{INTRODUCTION}

Sales of passenger cars increased sharply in North America after World War II. ${ }^{1}{ }^{2}$ Before this people had to rely on walking or on public transportation to get from place to place. To facilitate such activity, neighbourhoods were designed to be walkable. ${ }^{2}$ People lived in close proximity to services that were required for daily living and their streets were highly connected allowing for easy access to these services. ${ }^{2}$ With the advent of the automobile and the US Federal Highway Act of 1956 came a demand for the development of automobile-oriented neighbourhoods. $^{2-4}$ The majority of these neighbourhoods contained only residential homes, had long minimally connected street networks and had low population densities compared with prewar neighbourhoods. Owning a car and a home outside of the city 
was the new American dream. ${ }^{4}$ The problem with this new way of living was that people became dependent on their cars to do even the smallest errands. ${ }^{2}$ This loss of routine movement is hypothesised to be a contributor to the marked reduction in physical activity that has been observed in North America over the past 70 years. ${ }^{5}{ }^{6}$

In the hopes of recreating neighbourhoods that are supportive of walking, there is interest in identifying neighbourhood characteristics that are associated with higher levels of walking. ${ }^{78}$ Three constructs have consistently emerged as key determinants of walking. These include population density, diversity of destinations and pedestrian-friendly designs. ${ }^{9} 10$ The variables that best capture design, diversity and density are street connectivity, land use mix and residential density (collectively referred to as neighbourhood walkability). ${ }^{11} 12$

Higher density neighbourhoods with many amenities and well-connected streets have been linked to higher levels of utilitarian walking (ie, walking for specific purposes such as travel to work or school). ${ }^{13}{ }^{14}$ Utilitarian walking is only reasonably collected by self-report and represents a subset of total walking captured by biosensors. Given the potential for biases associated with selfreported measures of physical activity, ${ }^{15}{ }^{16}$ combining self-reported utilitarian walking with objective measures of total physical activity is advantageous. It allows researchers to isolate the policy-amenable subset of total physical activity (utilitarian walking) while also providing estimates of the potential for walkable environments to influence total physical activity.

The association of 'so-called' neighbourhood walkability with total walking-the more salient correlate of improved cardiometabolic health outcomes ${ }^{17-20}$-is less clear. While positive associations have been reported in some studies, ${ }^{21-23}$ studies in which researchers use researcher-assessed measures of neighbourhood walkability and/or biosensor-assessed metrics of total physical activity have been less likely to find important associations. ${ }^{8} 2425$ Given that there is a mismatch between perceived and researcher-assessed walkability, ${ }^{26-28}$ and that self-reported measures of physical activity may not capture actual levels of physical activity, ${ }^{16}{ }^{29}$ use of researcher-assessed measures of both neighbourhood features and physical activity is preferred when seeking to estimate the association between actual neighbourhood designs and total physical activity.

Numerous studies have been conducted on the association between biosensor-assessed physical activity (eg, minutes spent in moderate-to-vigorous intensity physical activity, MVPA) and Geographic Information System (GIS)-derived measures of street connectivity, land use mix, and population and/or population/residential density. ${ }^{80-32}$ Only six studies have specifically assessed this association using biosensor-assessed daily steps. ${ }^{33-38}$ Daily steps are an outcome of particular interest for the study of neighbourhood walkability for several reasons. First, daily steps provide an accurate estimate of total habitual physical activity. ${ }^{39}$ Much of this lower intensity activity is not captured by other commonly used biosensor-assessed measures, such as minutes spent in MVPA. Second, walking is the most common and preferred form of physical activity among adults. ${ }^{40}{ }^{41}$ Understanding if neighbourhood walkability is associated with daily steps among adults would suggest that neighbourhood-level interventions may have the potential to impart a benefit to large segments of the population. Third, daily steps are highly interpretable ${ }^{20}$ by both scientific and lay communities. This is unlike other biosensor-assessed metrics (eg, accelerometer counts) that may also be good at capturing total levels of physical activity, but are of less value when trying to explain the association of walkability with physical activity in an easily interpretable and relevant way. For example, saying that living in a high compared with a low walkable neighbourhood is associated with $\mathrm{x}$ more steps/day is more interpretable and readily understood by the public than saying that it is associated with $\mathrm{x}$ more activity counts.

Based on a recent systematic review and meta-analyses of studies that have been done using biosensor-assessed daily steps, we know that in Europe and in Asia, adults who live in high compared to low walkable neighbourhood accumulate 766 more steps/day (95\% credible interval: 250, 1271). ${ }^{42}$ This accounts for approximately $8 \%$ of recommended daily steps. We do not know, however, what this association is like in Canada. Since adults living in Europe and in Asia are more physically active than North American adults ${ }^{43}$ and might also have very different opinions regarding the importance of walking-friendly neighbourhoods, the influence of walkability on total physical activity may be different in the Canadian context. The Canadian studies that have been conducted to date have been restricted to a single city with limited variability in neighbourhood walkability and/or relatively small sample sizes. ${ }^{44-46}$ A large study $(n=151318)$ was published on the association of neighbourhood walkability as captured by the publicly available Walk Score with total, utilitarian and leisure-time walking, but the measures of physical activity were based on self-report. ${ }^{21}$ Studies with large variability in neighbourhood walkability, a population-based sample of adults, and researcher-assessed exposures and outcomes are needed to elucidate the role of neighbourhood walkability on total physical activity in the general Canadian adult population. This was the first study to estimate the association of researcher-assessed neighbourhood walkability (measured using GIS and the Walk Score) with both self-reported utilitarian walking and biosensorassessed total walking in a large sample of Canadian adults.

\section{METHODS}

\section{Study population}

The Canadian Health Measures Survey (CHMS) is a biennial population-based survey that collects data on a representative sample of Canadians. This study used 
data from cycle 1 (March 2007 to February 2009) of the CHMS. The sampling and recruitment strategy is explained in detail elsewhere. ${ }^{47}$ In brief, the CHMS employed a multistage sampling strategy collecting data from 15 sites from five regions across Canada: British Columbia (including the Yukon), the Prairies (Alberta, Manitoba, Saskatchewan and the Northwest Territories), Ontario, Québec and the Atlantic provinces (Newfoundland and Labrador, Prince Edward Island, Nova Scotia and New Brunswick). The number of data collection sites within each region was proportional to the size of the population, with two sites in British Columbia, two sites in the Prairies, six sites in Ontario, four sites in Québec and one site in the Atlantic provinces. Sites had to have a population greater than 10000 and be accessible to respondents (ie, within $50 \mathrm{~km}$ in urban areas and $100 \mathrm{~km}$ in rural areas). Using data from the 2006 Canadian Census, all households within the 15 data collection regions were stratified into one of five age groups $(6-11,12-19,20-39,40-59$ or $60-79$ years) using the respondents' age at the time of the census. This ensured that the dwellings in each stratum had a high probability of having at least one occupant in the desired age range. From these strata, a simple random sample of households was selected. Individuals living in Aboriginal communities or institutions or full-time members of the Canadian Forces were not eligible. Of the 8772 households that were contacted and requested to provide information on current household composition, 6106 complied (69.6\%). Using the household composition lists obtained from these households, 7483 individuals were requested to participate in the CHMS. In total, 6604 completed the household questionnaire $(88.3 \%)$. Of these, 5604 also visited the Medical Examination Centre (MEC) for assessments by medical professionals $(84.9 \%)$.

Access to the data was granted by the Social Sciences and Humanities Research Council of Canada (12-SSH-MCG-3081). ${ }^{47}$ Analyses were performed at the McGill-Concordia Quebec Inter-University Center for Social Statistics (QICSS).

\section{Exposure measures}

GIS-derived walkability

Home neighbourhoods were approximated using $500 \mathrm{~m}$ polygonal buffers around latitude-longitude coordinates that corresponded to the centroid of the participants' home postal codes. In the Canadian context, postal codes are accurate proxies for home addresses with $87.9 \%$ and $96.5 \%$ of postal codes falling within 200 and $500 \mathrm{~m}$ of the street address, respectively. ${ }^{48}$ Buffers were defined based on street networks. Streets that were not pedestrian-friendly (eg, highways) were excluded from the creation of the neighbourhood buffers. Five hundred-meter buffers were chosen as the scale of analysis as these approximated a $5-10 \mathrm{~min}$ walk from the home and would capture the environment to which the participants are most exposed. Land use mix, street connectivity and population density were calculated for each buffer using ArcMap V.10.1 (ESRI; Redlands, California, USA). Land use mix represented the degree of heterogeneity in residential, commercial, institutional/governmental and recreational land uses contained in each neighbourhood buffer. It was calculated using the commonly used entropy formula: ${ }^{11}{ }^{49}$ land use $\operatorname{mix}=(-1) \Sigma_{\mathrm{k}}\left(\mathrm{p}_{\mathrm{k}} \ln \mathrm{p}_{\mathrm{k}}\right) / \ln \mathrm{N}$ where $\mathrm{p}$ was the proportion of land area devoted to the specific land use $(\mathrm{k})$ in each buffer divided by $\ln ^{4}$ (Note: $\mathrm{p}$ Value was calculated as the land area devoted to a specific land use divided by the total area of walkable land uses.) The score ranged from 0 to 1 where a higher value indicated a greater diversity in land uses. Street connectivity was calculated as the number of $\geq 3$-way intersections per square kilometer in each neighbourhood buffer. Population density represented the unadjusted census population counts per square kilometer of the dissemination area in which each spatial coordinate fell. Land use mix and street connectivity were based on data obtained from the 2009 DMTI CanMap Streetfiles. ${ }^{50}$ Population density was based on the 2006 Canadian Census Population Counts File. $^{51}$ Similar to previously used methods, ${ }^{23} \quad 26 \quad 5253$ GIS-derived walkability was calculated by summing the z-scores of the three measures. A higher score indicated greater walkability.

\section{Walk Score}

The Walk Score is a validated measure of the walkability of a geographic location based on its proximity to 13 walkable destinations. ${ }^{54-56}$ The score ranges from 0 (cardependent) to 100 (walker's paradise), and is calculated based on an algorithm that assigns equal weights to each walkable destination. ${ }^{57}$ It is relevant to the construct of walkability as it reflects the diversity and density of neighbourhoods. A higher Walk Score is indicative of a greater diversity of services and also higher population density, which creates a higher demand for such services. ${ }^{11}$ Walk Scores were derived in two steps. First, the anonymous spatial coordinates were linked to postal codes using the 2009 Platinum Postal Suite Forward Sortation Areas file. ${ }^{58}$ The postal codes were then linked to the Walk Scores using the publicly available interface (http://www.walkscore.com).

\section{Outcome measures}

Daily steps

Ambulatory participants wore an accelerometer (Actical; Phillips Respironics, Oregon, USA) during waking hours on their right hip for seven consecutive days. The Actical accelerometer is a small lightweight device that measures acceleration in all directions. The step count function of the Actical has been validated in adults. ${ }^{59}$ Accelerometers were initialised to begin data collection at midnight following the MEC assessment. After 7 days, participants mailed the devices to Statistics Canada in postage-paid envelopes. Daily steps equalled the total 
steps accumulated divided by the number of days for which valid steps were recorded.

\section{Utilitarian walking}

Utilitarian walking was ascertained through a question that has been used in previous Canadian national health surveys: ${ }^{60}{ }^{61}$ In a typical week in the past 3 months, how many hours did you usually spend walking to work or to school or while doing errands (None, $<1,1-5,6-10,11-$ $20,>20 \mathrm{~h})$ ?

\section{Covariates}

Age, sex, married/common law status, children $\leq 15$ years in the household, immigrant status, total annual household income $\geq \$ 40000$, smoking status, presence of a mood disorder (depression, bipolar disorder, mania or dysthymia) and perceived health (poor, fair, good, very good, excellent) were assessed as part of the computer-assisted interview. A cut-off of $\geq \$ 40000$ for total annual household income was selected as it corresponded to the minimum income required to qualify a household with four members as middle class. ${ }^{62}$ Body mass index was based on height and weight measurements collected during the mobile clinic assessment. Season was based on the dates of the mobile clinic visits and corresponded to solstice calendar definitions of fall, winter, spring and summer. Rural/urban location was based on Canada Post's classification of rural/urban delivery areas. ${ }^{63}$

\section{Statistical analyses}

Descriptive statistics were produced for all variables of interest. Spearman correlation coefficients and scatter plots were used to examine the associations between steps/day, GIS-derived walkability and the Walk Score. Linear regression models were used to estimate mean differences in steps/day across quartiles of walkability. Logistic regression models were used to estimate the odds of walking $\geq 1 \mathrm{~h} /$ week for utilitarian purposes across quartiles of walkability. A cut-off of $\geq 1 \mathrm{~h}$ /week was selected based on the distribution of the data and the cut-offs that have been used in previous studies. ${ }^{25}$ 64-66 Associations were estimated across quartiles of walkability. To facilitate interpretation of these quartiles, the descriptive characteristics of the neighbourhoods that were included in each quartile were produced. A series of models were fitted-unadjusted, partially adjusted and fully adjusted-for the variables identified a priori as potential confounders and/or predictors of interest. Final models were based on complete case data. The association between steps/day and utilitarian walking was explored graphically and by calculating mean differences in steps/day across categories of self-reported hours/week spent in utilitarian walking (ie, $<1,1-5, \geq 6$ ), adjusted for GIS-derived walkability and all of the variables included in the fully adjusted regression models.

The choice of the geographic scale at which neighbourhoods are defined may influence the estimated associations between neighbourhood walkability and walking. ${ }^{6768}$ To address this issue, we conducted sensitivity analyses to assess if varying the sizes and shapes of neighbourhood buffers used in the calculation of the GIS-derived walkability index (ie, $1000 \mathrm{~m}$ polygonal buffers; 500 and $1000 \mathrm{~m}$ line-based buffers) would meaningfully alter the regression results. We also conducted sensitivity analyses to determine if changing the $\geq 1 \mathrm{~h} /$ week threshold for utilitarian walking to $\geq 6 \mathrm{~h}$ / week would meaningfully alter conclusions. Given that the purpose of this study was not to estimate Canada-wide mean values, all of the analyses were unweighted. Statistical analyses were conducted using SAS V.9.4 (SAS Institute Inc, Cary,North Carolina, USA).

\section{RESULTS}

\section{Descriptive statistics}

Of the 6604 individuals who participated in cycle 1 of the CHMS, 3727 adults ( $\geq 18$ years) completed the computerassisted interview and attended the mobile clinic assessment. Of these, $3586(96.2 \%)$ agreed to wear the accelerometer. Valid step count data were available for 3424 adults $(95.5 \%)$, with the majority of participants $(86.5 \%)$ wearing their accelerometers for 7 days. Complete exposure, outcome and covariate data were available for 2949 participants. Participants were on average middle-aged (mean 46.6 years, $\mathrm{SD}=16.4$ ) and accumulated a mean of 7923 steps/day ( $\mathrm{SD}=3792$; table 1 ).

On average, neighbourhoods had a land use mix of $0.20(\mathrm{SD}=0.23$; range: $0-1), 53 \geq 3$-way intersections $/ \mathrm{km}^{2}$ $(\mathrm{SD}=31), 4646$ residents $/ \mathrm{km}^{2} \quad(\mathrm{SD}=24260)$ and were 'car-dependent' based on the Walk Score's definition of walkability $($ mean $=46, \mathrm{SD}=30)$. The characteristics of the study neighbourhoods by quartile of GIS-derived neighbourhood walkability are presented in table 2 .

Participants with complete covariate data $(n=2949)$ who accumulated more daily steps included higher proportions of married/common law individuals, individuals with good-to-excellent perceived health and individuals with total annual household incomes $\geq \$ 40000$, and also included lower proportions of women, immigrants and ever smokers than participants without complete covariate data $(n=778$; see online supplemental file 1).

There was a graded association between daily steps and self-reported time spent in utilitarian walking, with greater utilitarian walking associated with higher daily steps (figure 1). Participants who reported more utilitarian walking (hours/week) accumulated more steps $(<1$ : 6613 steps/day, $95 \%$ CI 6251 to $6975 ; 1$ to 5 : 6768 steps/ day, $95 \%$ CI 6420 to $7117 ; \geq 6: 7391$ steps/day, $95 \%$ CI 6972 to 7811 ). Those who reported walking $\geq 6 \mathrm{~h} /$ week walked 623 more steps/day (95\% CI 261 to 986) than participants who reported walking $1-5 \mathrm{~h}$ /week, and 779 more steps/day (95\% CI 399 to 1159) than participants who reported walking $<1 \mathrm{~h} /$ week. The mean difference between participants who reported walking $1-5 \mathrm{~h} /$ week 
Table 1 Characteristics of Canadian adults who participated in cycle 1 (2007-2009) of the Canadian Health Measures Survey and on whom complete covariate data were available $(\mathrm{N}=2949)$

\begin{tabular}{|c|c|c|}
\hline & Mean & SD \\
\hline Age, years & 46.6 & 16.4 \\
\hline Steps/day & 7923 & 3792 \\
\hline \multirow[t]{2}{*}{ Body mass index, $\mathrm{kg} / \mathrm{m}^{2}$} & 27.3 & 5.5 \\
\hline & Percent & $\mathbf{N}$ \\
\hline Being a woman (vs being a man) & 51.4 & 1515 \\
\hline $\begin{array}{l}\text { Married/common law (vs widowed, } \\
\text { separated, divorced or single/never } \\
\text { married) }\end{array}$ & 65.1 & 1919 \\
\hline $\begin{array}{l}\text { Have children } \leq 15 \text { years old in } \\
\text { household (yes vs no) }\end{array}$ & 35.6 & 1051 \\
\hline Immigrant (yes vs no) & 19.9 & 587 \\
\hline Mood disorder (yes vs no) & 8.3 & 246 \\
\hline $\begin{array}{l}\text { Good/very good/excellent perceived } \\
\text { health (vs fair/poor) }\end{array}$ & 90.3 & 2662 \\
\hline $\begin{array}{l}\text { Total annual household income } \\
\geq \$ 40000 \text { (vs }<\$ 40000)\end{array}$ & 77.7 & 2291 \\
\hline Ever smoker (vs Never-smoker) & 50.5 & 1488 \\
\hline $\begin{array}{l}\text { Fall/winter assessment (vs spring/ } \\
\text { summer assessment) }\end{array}$ & 48.5 & 1429 \\
\hline Rural location (vs urban location) & 14.4 & 424 \\
\hline $\begin{array}{l}\geq 1 \mathrm{~h} / \text { week of utilitarian walking (vs }<1 \mathrm{~h} / \\
\text { week) }\end{array}$ & 63.7 & 1878 \\
\hline $\begin{array}{l}\geq 6 \mathrm{~h} / \text { week of utilitarian walking (vs }<6 \mathrm{~h} / \\
\text { week) }\end{array}$ & 17.8 & 526 \\
\hline
\end{tabular}

for utilitarian purposes and those who reported walking $<1 \mathrm{~h} /$ week was 155 steps/day (95\% CI -138 to 448$)$.

\section{Correlation analyses}

GIS-derived walkability and the Walk Score were highly correlated ( $\mathrm{R}=0.82,95 \%$ CI 0.80 to 0.83$)$. Neither walkability measure was correlated with average steps/day (GIS-derived walkability: $\mathrm{R}=-0.03,95 \%$ CI -0.07 to 0.004; Walk Score: $\mathrm{R}=-0.03,95 \%$ CI -0.06 to 0.01 ).

\section{Multivariable models}

Daily steps

Point estimates suggested negative associations between neighbourhood walkability and steps/day (eg, highest vs lowest GIS-derived walkability quartile: -234 steps/day,
95\% CI -630 to 163; highest vs lowest Walk Score quartile: -232 steps/day, 95\% CI -631 to 167), but CIs suggest null associations (table 3 ). The results were comparable when using variable buffer shapes and sizes (see online supplemental file 2).

\section{Utilitarian walking}

Living in the highest compared with the lowest quartile of GIS-derived walkability was associated with a $66 \%$ increased odds of walking $\geq 1 \mathrm{~h} /$ week for utilitarian purposes (95\% CI 1.31 to 2.11). Living in the highest compared with the lowest Walk Score quartile was associated with twofold increased odds of utilitarian walking $(\mathrm{OR}=2.00,95 \%$ CI 1.57 to 2.54 ; table 4$)$. Higher odds of utilitarian walking were also observed for the third quartiles of GIS-derived walkability and the Walk Score compared with the first quartiles, albeit smaller than for the fourth quartiles. No conclusive associations were observed for the second compared with the first quartiles of either of the walkability measures. Similar associations were observed when using $1000 \mathrm{~m}$ polygonal network buffers, and 500 and $1000 \mathrm{~m}$ line-based buffers for GIS-derived walkability (see online supplemental file 2) and when using a cut-off of $\geq 6 \mathrm{~h} /$ week (see online supplemental file 3).

\section{DISCUSSION}

No important associations were observed between walkability and daily steps. A positive graded association was observed between neighbourhood walkability and odds of self-reported utilitarian walking. Participants who reported walking $\geq 6 \mathrm{~h} /$ week walked 623 more steps/day than participants who reported walking $1-5 \mathrm{~h} /$ week, and 779 more steps/day than participants who reported walking $<1 \mathrm{~h} /$ week.

Four previous studies compared the daily steps of adults living in low and high walkable neighbourhoods, using measures similar to ours. Two were conducted in Belgium, ${ }^{34} 35$ one in the Czech Republic ${ }^{36}$ and one in Japan. ${ }^{37}$ In the Czech study, ${ }^{38}$ participants living in high compared with low walkable neighbourhoods accumulated 2088 more steps/day (95\% CI 440 to 3736). In one of the Belgian studies, ${ }^{34}$ participants living in high compared with low walkable neighbourhoods accumulated 1222 more steps/day (95\% CI 131 to 2313). Although

Table 2 Characteristics of the study neighbourhoods by quartile of Geographic Information System (GIS)-derived neighbourhood walkability $(n=2949)$

\begin{tabular}{|c|c|c|c|c|c|c|c|c|}
\hline & \multicolumn{2}{|c|}{$\begin{array}{l}\text { Street connectivity } \\
\text { Number of } \geq 3 \text { way } \\
\text { intersections } / \mathrm{km}^{2}\end{array}$} & \multicolumn{2}{|c|}{$\begin{array}{l}\text { Land use mix } \\
\text { Range: } 0-1\end{array}$} & \multicolumn{2}{|c|}{$\begin{array}{l}\text { Population density } \\
\text { Population count } / \mathbf{k m}^{2}\end{array}$} & \multicolumn{2}{|c|}{ Walk Score } \\
\hline & Mean & SD & Mean & SD & Mean & SD & Mean & SD \\
\hline Quartile 1 & 12 & 13 & 0.003 & 0.02 & 173 & 452 & 10 & 17 \\
\hline Quartile 2 & 52 & 13 & 0.05 & 0.09 & 1464 & 1884 & 41 & 18 \\
\hline Quartile 3 & 64 & 18 & 0.25 & 0.15 & 3050 & 3332 & 57 & 19 \\
\hline Quartile 4 & 82 & 24 & 0.50 & 0.16 & 13882 & 47130 & 77 & 18 \\
\hline
\end{tabular}


Figure 1 Daily step counts by self-reported time spent in utilitarian walking $(\mathrm{n}=2949)$.

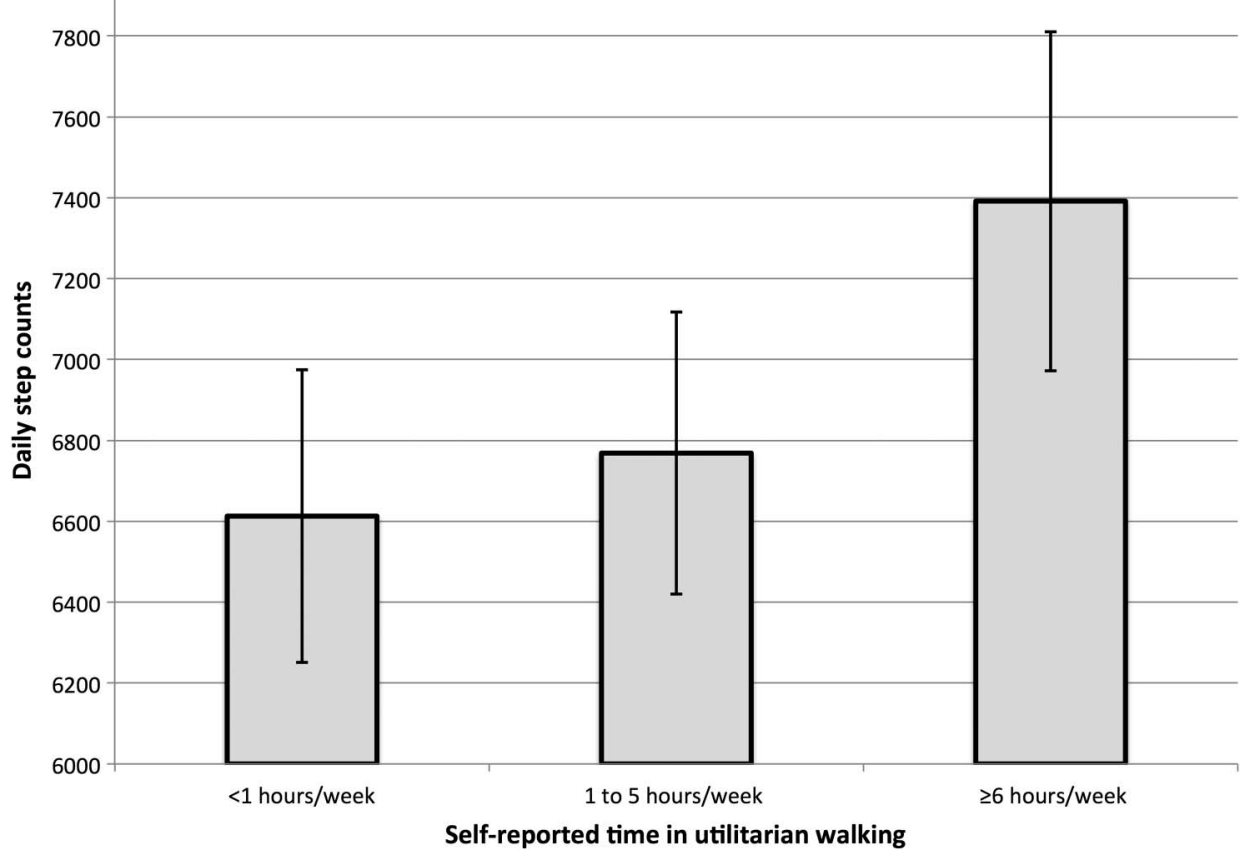

the estimates of the other Belgian study ${ }^{35}$ and the Japanese study $^{37}$ were not conclusive, these also suggested a positive association between walkability and steps. The settings of these studies differ importantly from the Canadian context, possibly accounting for the difference in findings. In contrast to the Czech Republic, Belgium and Japan, there is a heavy reliance on cars in Canada. ${ }^{69}$ Neighbourhood walkability, therefore, may not influence travel choices of Canadians sufficiently to affect total steps. While there were no associations between walkability and daily steps when comparing quartiles 3 and 4 to quartile 1 of GIS-derived walkability and when comparing quartile 4 to 1 of the Walk Score, steps were lower in quartile 2 of GIS-derived walkability and quartiles 3 and 2 of the Walk Score when compared with the first quartiles of these measures. This is counter intuitive as it suggests that more walkable neighbourhoods are associated with lower daily steps. This may be a result of quartile 1 being representative of suburban neighbourhoods characterised by good access to public transit. It has been demonstrated that even in very low walkable neighbourhoods, if there are transit stops, residents will walk to board express buses and trains. ${ }^{70}$ It may also be a result of the desirable aesthetic or other features in suburban environments that encourage leisure walking.

We identified a positive association of GIS-derived walkability and the Walk Score with self-reported utilitarian walking. This is consistent with prior studies. ${ }^{16}$ 27-30 Participants $(\mathrm{n}=1875)$ in Calgary (Alberta, Canada) living in high compared with low walkable neighbourhoods (based on GIS-derived measures) had a 50\% higher odds of walking $\geq 10 \mathrm{~min} /$ week for utilitarian purposes in the last week compared with those who did not $(\mathrm{OR}=1.50,95 \%$ CI 0.94 to 2.41$) .^{71}$ In a study of 438 adults living in Ghent Belgium, participants who lived in high compared with low walkable neighbourhoods reported more utilitarian walking $(76 \mathrm{~min} /$ week vs $16.7 \mathrm{~min} /$ week). ${ }^{72}$ Similarly, in an analysis of 4552 adults who participated in the Multi-Ethnic Study of Atherosclerosis, every 10-point increase in the Walk Score was associated with $14 \%$ higher odds of walking for utilitarian purposes $(\mathrm{OR}=1.14,95 \%$ CI 1.09 to 1.18$) .^{73}$

We were particularly interested in the subgroup of studies that, like ours, concurrently examined the relationship of walkability with utilitarian walking and total walking. The advantage of these studies is that they allow for within-study comparisons of effects. Our findings are consistent with those of American studies conducted on the association between walkability and self-reported utilitarian walking, and total physical activity assessed via self-report or biosensor-assessed metrics. ${ }^{8} 2574$ For example, in a nationally representative sample of 1224 American adults, every 10-point increase in the Walk Score was associated with a $8 \%$ higher odds of walking at least $10 \mathrm{~min}$ in the past week for utilitarian purposes $(\mathrm{OR}=1.08,95 \%$ CI 1.01 to 1.14$)$, but no association was observed for total self-reported minutes/week spent walking. ${ }^{25}$ Our findings are less consistent with studies conducted in Europe and Asia on the association between GIS-derived walkability and self-reported utilitarian walking and biosensor-assessed daily steps. In two Belgian studies, participants living in high compared with low walkable neighbourhoods engaged $81.5 \mathrm{~min} /$ week more (95\% CI 66.9 to 96.1$)^{33}$ and $75.6 \mathrm{~min} /$ week more $(95 \% \text { CI } 68.3 \text { to } 83.1)^{34}$ in utilitarian walking. No meaningful association was identified between walkability and utilitarian walking in a Japanese study $(-4.7 \mathrm{~min} /$ day more, $95 \%$ CI -10.2 to 0.80$) .{ }^{36}$ In contrast to our results, three studies signalled positive associations for daily steps (Belgian study: 548 more steps/ day, $95 \%$ CI -230 to $1326 ;{ }^{34}$ Belgian study: 1222 more 
Table 3 Univariate, partially adjusted and fully adjusted models representing the mean differences in accelerometer-assessed steps/day across quartiles of neighbourhood walkability $(n=2949)^{*}, \dagger, \ddagger$

\begin{tabular}{|c|c|c|c|c|c|c|c|c|c|c|}
\hline & \multicolumn{3}{|l|}{ Quartile 2} & \multicolumn{3}{|l|}{ Quartile 3} & \multicolumn{3}{|l|}{ Quartile 4} & \multirow[b]{3}{*}{$\mathbf{R}^{2}$} \\
\hline & \multirow[b]{2}{*}{$\begin{array}{l}\text { Steps/day } \\
\text { difference }\end{array}$} & \multicolumn{2}{|l|}{$95 \% \mathrm{Cl}$} & \multirow[b]{2}{*}{$\begin{array}{l}\text { Steps/day } \\
\text { difference }\end{array}$} & \multicolumn{2}{|l|}{$95 \% \mathrm{Cl}$} & \multirow[b]{2}{*}{$\begin{array}{l}\text { Steps/day } \\
\text { difference }\end{array}$} & \multicolumn{2}{|l|}{$95 \% \mathrm{Cl}$} & \\
\hline & & $\begin{array}{l}\text { Lower } \\
\text { bound }\end{array}$ & $\begin{array}{l}\text { Upper } \\
\text { bound }\end{array}$ & & $\begin{array}{l}\text { Lower } \\
\text { bound }\end{array}$ & $\begin{array}{l}\text { Upper } \\
\text { bound }\end{array}$ & & $\begin{array}{l}\text { Lower } \\
\text { bound }\end{array}$ & $\begin{array}{l}\text { Upper } \\
\text { bound }\end{array}$ & \\
\hline \multicolumn{11}{|c|}{ GIS-derived walkability } \\
\hline Model 1 & -357 & -744 & 30 & -389 & -776 & -2 & -471 & -858 & -84 & 0.0023 \\
\hline Model 2 & -412 & -787 & -37 & -538 & -913 & -162 & -744 & -1121 & -367 & 0.0681 \\
\hline Model 3 & -395 & -768 & -21 & -448 & -823 & -73 & -530 & -916 & -144 & 0.0865 \\
\hline Model 4 & -397 & -766 & -28 & -343 & -717 & 31 & -234 & -630 & 163 & 0.1093 \\
\hline \multicolumn{11}{|c|}{ Walk Score } \\
\hline Model 1 & -322 & -713 & 70 & -582 & -975 & -189 & -485 & -870 & -99 & 0.0033 \\
\hline Model 2 & -393 & -772 & -14 & -757 & -1137 & -376 & -772 & -1147 & -397 & 0.0698 \\
\hline Model 3 & -418 & -795 & -40 & -623 & -1005 & -242 & -555 & -941 & -169 & 0.0875 \\
\hline Model 4 & -390 & -763 & -18 & -538 & -917 & -158 & -232 & -631 & 167 & 0.1104 \\
\hline
\end{tabular}

${ }^{*}$ Quartile 1 (least walkable) served as the reference; GIS-derived walkability index quartiles: $<-1.5, \geq 1.5,<-0.3, \geq-0.3,<1.1, \geq 1.1$; Walk Score quartiles: $<22, \geq 22,<48, \geq 48,<68, \geq 68$.

†Model 1: unadjusted; model 2: adjusted for age, sex and body mass index; model 3: adjusted for age, sex, body mass index, married/ common law, income, children, immigrant and mood disorder; model 4: adjusted for age, sex, body mass index, married/common law, income, children, immigrant, mood disorder, perceived health, ever smoker and season.

†Rural location was not included in the final multivariate models as it was correlated with both GIS-derived walkability and the Walk Score.

GIS, Geographic Information System.

steps/day, $95 \%$ CI 131 to $2313 ;^{33}$ Japanese study: 1070 steps/day, $95 \%$ CI -400 to 2540$).{ }^{36}$

Canadians living in more walkable neighbourhoods had higher odds of reporting more utilitarian walking. Although encouraging utilitarian walking may lead to increases in daily steps, we are not able to conclude that walkability is associated with the number of total steps/ day that Canadian adults achieve. In interpreting these results, there are some limitations to note. First, some misclassification bias is expected with the use of selfreported utilitarian walking. There are no biosensors, however, that can capture walking purposes, necessitating reliance on self-report. Participants were asked to report their utilitarian walking in the past 3 months and this could mean that the season of assessment (a covariate in fully adjusted models) may not have been timematched to the self-reported utilitarian walking. However, even if all of the participants at the border of the seasonal categories (fall/winter and spring/ summer) reported utilitarian walking based on a different season, assuming up to a 4-week mismatch period that would occur twice every sixth month, only a

Table 4 Odds of $\geq 1 \mathrm{~h} /$ week of utilitarian walking $(\mathrm{OR}, 95 \% \mathrm{Cl})$ in univariate, partially adjusted and fully adjusted models across quartiles of neighbourhood walkability $(n=2949)^{*}, \dagger, \ddagger$

\begin{tabular}{|c|c|c|c|c|c|c|c|c|c|c|}
\hline & \multicolumn{3}{|c|}{ Quartile 2} & \multicolumn{3}{|c|}{ Quartile 3} & \multicolumn{3}{|c|}{ Quartile 4} & \multirow[b]{3}{*}{$\begin{array}{l}\text { Pseudo } \\
\mathbf{R}^{2}\end{array}$} \\
\hline & \multirow[b]{2}{*}{ OR } & \multicolumn{2}{|l|}{$95 \% \mathrm{Cl}$} & \multirow[b]{2}{*}{ OR } & \multicolumn{2}{|l|}{$95 \% \mathrm{Cl}$} & \multirow[b]{2}{*}{ OR } & \multicolumn{2}{|l|}{$95 \% \mathrm{Cl}$} & \\
\hline & & $\begin{array}{l}\text { Lower } \\
\text { bound }\end{array}$ & $\begin{array}{l}\text { Upper } \\
\text { bound }\end{array}$ & & $\begin{array}{l}\text { Lower } \\
\text { bound }\end{array}$ & $\begin{array}{l}\text { Upper } \\
\text { bound }\end{array}$ & & $\begin{array}{l}\text { Lower } \\
\text { bound }\end{array}$ & $\begin{array}{l}\text { Upper } \\
\text { bound }\end{array}$ & \\
\hline \multicolumn{11}{|c|}{ GIS-derived walkability } \\
\hline Model 1 & 1.19 & 0.97 & 1.47 & 1.64 & 1.33 & 2.02 & 2.19 & 1.76 & 2.73 & 0.0201 \\
\hline Model 2 & 1.16 & 0.94 & 1.42 & 1.58 & 1.28 & 1.96 & 2.13 & 1.71 & 2.66 & 0.0325 \\
\hline Model 3 & 1.14 & 0.92 & 1.40 & 1.53 & 1.23 & 1.90 & 1.97 & 1.57 & 2.48 & 0.0358 \\
\hline Model 4 & 1.13 & 0.91 & 1.39 & 1.41 & 1.14 & 1.76 & 1.66 & 1.31 & 2.11 & 0.0475 \\
\hline \multicolumn{11}{|l|}{ Walk Score } \\
\hline Model 1 & 1.14 & 0.93 & 1.40 & 1.87 & 1.51 & 2.32 & 2.56 & 2.06 & 3.19 & 0.0318 \\
\hline Model 2 & 1.11 & 0.90 & 1.37 & 1.85 & 1.49 & 2.30 & 2.50 & 2.01 & 3.12 & 0.0443 \\
\hline Model 3 & 1.11 & 0.90 & 1.37 & 1.79 & 1.44 & 2.24 & 2.37 & 1.88 & 2.98 & 0.0460 \\
\hline Model 4 & 1.09 & 0.88 & 1.35 & 1.70 & 1.36 & 2.12 & 2.00 & 1.57 & 2.54 & 0.0555 \\
\hline \multicolumn{11}{|c|}{$\begin{array}{l}\text { *Quartile } 1 \text { (least walkable) served as the reference; GIS-derived walkability index quartiles: }<-1.5, \geq 1.5,<-0.3, \geq-0.3,<1.1, \geq 1.1 ; \text { Walk } \\
\text { Score quartiles: }<22, \geq 22,<48, \geq 48,<68, \geq 68 \text {. } \\
\text { †Model 1: unadjusted; model } 2 \text { : adjusted for age, sex and body mass index; model } 3 \text { : adjusted for age, sex, body mass index, married/ } \\
\text { common law, income, children, immigrant and mood disorder; model } 4 \text { : adjusted for age, sex, body mass index, married/common law, } \\
\text { income, children, immigrant, mood disorder, perceived health, ever smoker and season. } \\
\text { †Rural location was not included in the final multivariate models as it was correlated with both GIS-derived walkability and the Walk Score. } \\
\text { GIS, Geographic Information System. }\end{array}$} \\
\hline
\end{tabular}


maximum of $4.7 \%$ of participants could have a mismatch between season and utilitarian walking. This is not expected to importantly bias the results of this study. Second, given the cross-sectional nature of this study, conclusions regarding causality and directionality of the associations could not be made and studies evaluating cross-sectional neighbourhood exposures are limited by selection into and out of areas in ways that are likely correlated with the outcomes. Third, two potential confounders (ie, car ownership and residential self-selection $^{30} 53{ }^{75-77}$ ) could not be accounted for in our analyses. Fourth, our measures of walking were not context specific. We do not know how much of the reported utilitarian walking and the accumulated number of steps occurred in the home neighbourhood. Studies on the association between neighbourhood walkability and neighbourhood-based physical activity are emerging, ${ }^{78}{ }^{79}$ but these have a high-respondent burden and are not generally feasible for national-scale studies like that presented here. Fifth, there is a possibility of selection bias given minor differences between participants who were included and excluded from the final analyses. Sixth, we focused on the associations of walking with large-scale features of neighbourhood designs. We acknowledge there are other potentially important features of the built environment (eg, aesthetics, neighbourhood safety, presence of crosswalks, transit stops) that may be associated with both utilitarian and/or total walking. ${ }^{66}$ Seventh, walking was assessed for up to 7 days, a snapshot that may not be representative of habitual walking levels. If steps were measured over a longer period of time, an association between walkability and daily steps may have emerged. Designing studies where participants are compliant with wearing devices over longer periods of time, however, is difficult.

Despite these limitations, there are several strengths to our study and valuable conclusions that can be drawn. Strengths include a large sample size, biosensor-assessed daily steps, and consideration of individual and area-level covariates (including clinical measures of height and weight). All of these allowed for increased precision in the estimation of associations and minimised the risk of residual confounding. Other strengths include the use of multiple measures of walkability and the inclusion of a wide variety of neighbourhoods from across Canada.

The findings of this study suggest that increasing utilitarian walking may lead to increases in daily steps and that increasing walkability may also lead to increases in utilitarian walking. There was, however, no evidence, that walkability was associated with total daily steps. Given that utilitarian walking is a subcomponent of total daily steps, the important role that walkability may have in increasing utilitarian walking should not be discounted. In Canada, while enhancing walkability may lead to increases in utilitarian walking, other factors will need to be leveraged to promote increases in total walking.
Acknowledgements The analyses presented in this paper were conducted at the Quebec Inter-University Centre for Social Statistics (QICSS), which is part of the Canadian Research Data Centre Network (CRDCN). The services and activities provided by the QICSS are made possible by the financial or in-kind support of the SSHRC, the CIHR, the CFI, Statistics Canada, the FRQSC and the Quebec universities. The authors thank Paul A Peters for deriving the spatial location data, and making these and the environmental data that were derived available for analyses in the McGill-Concordia QICSS. The authors also thank Camille Ouellet Dallaire and Ruilan Shi for their assistance with Geographic Information Systems mapping, and Colin Stewart for retrieving the Walk Score data.

Contributors SH conducted the statistical analyses and wrote the manuscript. $\mathrm{SH}$ had full access to the data, and takes responsibility for the integrity of the data and the accuracy of the analysis. KD, NAR and SH developed the study questions. KD and NAR contributed to discussions regarding the analytical methods and to the writing of the manuscript. LJ provided guidance regarding the statistical analyses and reviewed the manuscript for content. All authors contributed to the interpretation of data, reviewed the manuscript for content and approved the final manuscript for submission.

Funding This work was supported by the Canadian Institutes of Health Research (CIHR) through a Doctoral Research Award provided to SH. Support to SH was also provided by a Quebec Inter-University Centre for Social Statistics Matching Grant. KD is supported through a Senior Clinician Scientist Award from the Fonds de Recherché du Québec-Santé (FRQ-S). SH was supported by a FRQ-S Career Award (Chercheurs Boursier Junior 2).

Competing interests None declared.

Ethics approval Health Canada Research Ethics Board.

Provenance and peer review Not commissioned; externally peer reviewed.

Data sharing statement Access to the data was granted by the Social Sciences and Humanities Research Council of Canada (SSHRC). All analyses reported in the study were performed at the McGill-Concordia Quebec Inter-University Center for Social Statistics (QICSS). The data reported in this study are available in an affiliated research data centre to anyone who requests access and are approved by SSHRC/Statistics Canada.

Open Access This is an Open Access article distributed in accordance with the Creative Commons Attribution Non Commercial (CC BY-NC 4.0) license, which permits others to distribute, remix, adapt, build upon this work noncommercially, and license their derivative works on different terms, provided the original work is properly cited and the use is non-commercial. See: http:// creativecommons.org/licenses/by-nc/4.0/

\section{REFERENCES}

1. Foster M. A nation on wheels: the automobile culture in America since 1945. Belmont, MA: Thomson Learning, 2003.

2. Newman P. Walking in a historical, international and contemporary context. In: Tolley R, ed. Sustainable trasnport: planning for walking and cycling in urban envionments. Abington Hall, Abington; Cambridge, England: Woodhead Publishing Limited, 2003:48-58.

3. Speck J. Walkable city: how downtown can save North America, one step at a time. New York: Farrar, Straus and Giroux, 2012.

4. Frumkin $\mathrm{H}$, Frank L, Jackson R. Urban sprawl and public health: designing, planning, and building for healthy communities. Washington DC: Island Press, 2004.

5. French SA, Story M, Jeffery RW. Environmental influences on eating and physical activity. Annu Rev Public Health 2001;22:309-35.

6. Handy SL, Cao X, Mokhtarian PL. Self-selection in the relationship between the built environment and walking. J Am Plann Assoc 2006;72:54-74.

7. Handy SL, Boarnet MG, Ewing R, et al. How the built environment affects physical activity: views from urban planning. Am J Prev Med 2002;23(2 Suppl):64-73.

8. Oakes JM, Forsyth A, Schmitz KH. The effects of neighborhood density and street connectivity on walking behavior: the Twin Cities walking study. Epidemiol Perspect Innov 2007;4:16.

9. Cervero R. Travel demand and the 3Ds: density, diversity, and design. Transpn Res 1997;2:199-219.

10. Smith KR, Brown BB, Yamada I, et al. Walkability and body mass index density, design, and new diversity measures. Am J Prev Med 2008;35:237-44. 
11. Leslie E, Coffee N, Frank L, et al. Walkability of local communities: using geographic information systems to objectively assess relevant environmental attributes. Health Place 2007;13:111-22.

12. Saelens BE, Sallis JF, Frank LD. Environmental correlates of walking and cycling: findings from the transportation, urban design, and planning literatures. Ann Behav Med 2003;25:80-91.

13. Grasser G, Van Dyck D, Titze S, et al. Objectively measured walkability and active transport and weight-related outcomes in adults: a systematic review. Int J Public Health 2013;58: $615-25$

14. Saelens BE, Handy SL. Built environment correlates of walking: a review. Med Sci Sports Exerc 2008;40(7 Suppl):S550-66.

15. Schmidt MD, Cleland VJ, Thomson RJ, et al. A comparison of subjective and objective measures of physical activity and fitness in identifying associations with cardiometabolic risk factors. Ann Epidemiol 2008; 18:378-86.

16. Lim S, Wyker B, Bartley K, et al. Measurement error of self-reported physical activity levels in New York City: assessment and correction. Am J Epidemiol 2015;181:648-55.

17. Yates T, Haffner SM, Schulte PJ, et al. Association between change in daily ambulatory activity and cardiovascular events in people with impaired glucose tolerance (NAVIGATOR trial): a cohort analysis. Lancet 2014;383:1059-66.

18. Gilmour H. Physically active Canadians. Health Rep 2007;18:45-65.

19. Tudor-Locke C, Bassett DR, Swartz AM, et al. A preliminary study of one year of pedometer self-monitoring. Ann Behav Med 2004;28:158-62.

20. Tudor-Locke C, Bassett DR Jr. How many steps/day are enough? Preliminary pedometer indices for public health. Sports Med 2004;34:1-8.

21. Thielman J, Rosella L, Copes R, et al. Neighborhood walkability: differential associations with self-reported transport walking and leisure-time physical activity in Canadian towns and cities of all sizes. Prev Med 2015;77:174-80.

22. Kerr J, Norman G, Millstein R, et al. Neighborhood environment and physical activity among older women: findings from the San Diego Cohort of the Women's Health Initiative. J Phys Act Health 2014;11:1070-7.

23. Christian HE, Bull FC, Middleton NJ, et al. How important is the land use mix measure in understanding walking behaviour? Results from the RESIDE study. Int J Behav Nutr Phys Act 2011;8:55.

24. Ferdinand $A O$, Sen $B$, Rahurkar $S$, et al. The relationship between built environments and physical activity: a systematic review. $A m J$ Public Health 2012;102:e7-13.

25. Tuckel P, Milczarski W. Walk Score (TM), perceived neighborhood walkability, and walking in the US. Am J Health Behav 2015;39:242-56.

26. Hajna S, Dasgupta K, Halparin M, et al. Neighborhood walkability: field validation of geographic information system measures. $\mathrm{Am} \mathrm{J}$ Prev Med 2013:44:e51-5.

27. McCormack GR, Cerin E, Leslie E, et al. Objective versus perceived walking distances to destinations: correspondence and predictive validity. Environ Behav 2008:40:401-25.

28. Gebel K, Bauman AE, Sugiyama T, et al. Mismatch between perceived and objectively assessed neighborhood walkability attributes: prospective relationships with walking and weight gain. Health Place 2011;17:519-24.

29. Garriguet D, Tremblay S, Colley RC. Comparison of Physical Activity Adult Questionnaire results with accelerometer data. Health Rep 2015;26:11-17.

30. Ding D, Sallis JF, Norman GJ, et al. Neighborhood environment and physical activity among older adults: do the relationships differ by driving status? J Aging Phys Act 2014;22:421-31.

31. Saelens BE, Sallis JF, Black JB, et al. Neighborhood-based differences in physical activity: an environment scale evaluation. $A m$ J Public Health 2003;93:1552-8.

32. De Meester F, Van Dyck D, De Bourdeaudhuij I, et al. Active living neighborhoods: is neighborhood walkability a key element for Belgian adolescents? BMC Public Health 2012:12:7.

33. Van Dyck D, Deforche B, Cardon G, et al. Neighbourhood walkability and its particular importance for adults with a preference for passive transport. Health Place 2009;15:496-504.

34. Van Dyck D, Cardon G, Deforche B, et al. Urban-rural differences in physical activity in Belgian adults and the importance of psychosocial factors. J Urban Health 2011;88:154-67.

35. Dygryn J, Mitas J, Stelzer J. The influence of built environment on walkability using geographic information system. J Hum Kinetics 2010;24:93-9.

36. Kondo K, Lee JS, Kawakubo K, et al. Association between daily physical activity and neighborhood environments. Environ Health Prev Med 2009;14:196-206.
37. Robertson LB, Ward Thompson C, Aspinall P, et al. The influence of the local neighbourhood environment on walking levels during the Walking for Wellbeing in the West pedometer-based community intervention. J Environ Public Health 2012;2012:974786.

38. Zhang Y, Ning LD, Xin L. Relationship between built environment, physical activity, adiposity and health in adults aged $46-80$ in Shanghai, China. J Phys Act Health 2015;12:569-78.

39. Tudor-Locke CE, Bell RC, Myers AM, et al. Pedometer-determined ambulatory activity in individuals with type 2 diabetes. Diabetes Res Clin Pract. 2002;55(3):191-199.

40. Schneider PL, Crouter S, Bassett DR. Pedometer measures of free-living physical activity: comparison of 13 models. Med Sci Sports Exerc. 2004;36:331-5.

41. Gilmour H. Physically active Canadians. Health Reports. 2007;18:45-65.

42. Hajna S, Ross NA, Brazeau AS, et al. Associations between neighbourhood walkability and daily steps in adults: a systematic review and meta-analysis. BMC Public Health. 2015;15:768.

43. World Health Organization. Global health observatory: prevalence of insufficient physical activity. Geneva, Switzerland: World Health Organization, 2015. http://www.who.int/gho/ncd/risk_factors/ physical_activity_text/en/index.html (cited 17 February 2015).

44. McCormack GR, Shiell A, Doyle-Baker PK, et al. Subpopulation differences in the association between neighborhood urban form and neighborhood-based physical activity. Health Place 2014;28:109-15.

45. Riley DL, Mark AE, Kristjansson E, et al. Neighbourhood walkability and physical activity among family members of people with heart disease who participated in a randomized controlled trial of a behavioural risk reduction intervention. Health Place 2013;21:148-55.

46. Prince SA, Kristjansson EA, Russell K, et al. Relationships between neighborhoods, physical activity, and obesity: a multilevel analysis of a large Canadian city. Obesity (Silver Spring) 2012;20:2093-100.

47. Statistics Canada. Canadian Health Measures Survey (CHMS) Data User Guide: Cycle 1 2011; http://www23.statcan.gc.ca/imdb-bmdi/ document/5071_D2_T1_V1-eng.htm

48. Bow CJ, Waters NM, Faris PD, et al. Accuracy of city postal code coordinates as a proxy for location of residence. Int $J$ Health Geogr 2004;3:5.

49. Hajna S, Dasgupta $K$, Joseph $L$, et al. A call for caution and transparency in the calculation of land use mix: measurement bias in the estimation of associations between land use mix and physical activity. Health Place 2014;29:79-83.

50. DMTI Spatial Inc. CanMap Streetfiles. v2009.3. Markham, Ontario: DMTI Spatial Inc., 2009.

51. Statistics Canada. Unadjusted 2006 Canadian Census Population Counts File. Census Ottawa: Statistics Canada, 2006.

52. Frank LD, Schmid TL, Sallis JF, et al. Linking objectively measured physical activity with objectively measured urban form: findings from SMARTRAQ. Am J Prev Med 2005;28(2 Suppl 2):117-25.

53. Frank LD, Saelens BE, Powell KE, et al. Stepping towards causation: do built environments or neighborhood and travel preferences explain physical activity, driving, and obesity? $\mathrm{Soc} \mathrm{Scl}$ Med 2007:65:1898-914.

54. Carr LJ, Dunsiger SI, Marcus BH. Validation of Walk Score for estimating access to walkable amenities. Br J Sports Med 2011;45:1144-8.

55. Carr LJ, Dunsiger SI, Marcus BH. Walk score as a global estimate of neighborhood walkability. Am J Prev Med 2010;39:460-3.

56. Duncan DT. What's your Walk Score(R)?: web-based neighborhood walkability assessment for health promotion and disease prevention. Am J Prev Med 2013;45:244-5.

57. Carr LJ, Dunsiger SI, Marcus BH. Walk Score ${ }^{\mathrm{TM}}$ as a global estimate of neighborhood walkability. Am J Prev Med 2010;39:460-3.

58. DMTI Spatial Inc. Platinum Postal Suite: CanMap Forward Sortation Area Boundaries. [computer file]. Markham, 2009.

59. Esliger DW, Probert A, Connor Gorber S, et al. Validity of the Actical accelerometer step-count function. Med Sci Sports Exerc 2007;39:1200-4.

60. Government of Canada. Aboriginal Peoples Survey, 2006: an overview of the health of the Métis population. Statistics Canada, 2006.

61. Government of Canada. National Population Health Survey: Household Component-Longitudinal Cycle 9 (2010-2011) Questionnaire. Ottawa: Statistics Canada, 2009.

62. McMahon T. Who belongs to Canada's middle class? Macleans. 2014. (cited 19 August 2015). http://www.macleans.ca/economy/ who-belongs-to-canadas-middle-class/

63. Statistics Canada. How postal codes map to geographic areas. Geography Working Paper Series, 2007. 
64. Rodríguez DA, Evenson KR, Diez Roux AV, et al. Land use, residential density, and walking. The multi-ethnic study of atherosclerosis. Am J Prev Med 2009;37:397-404.

65. Knuiman MW, Christian HE, Divitini ML, et al. A longitudinal analysis of the influence of the neighborhood built environment on walking for transportation: the RESIDE study. Am J Epidemiol 2014:180:453-61.

66. Doescher MP, Lee C, Berke EM, et al. The built environment and utilitarian walking in small U.S. towns. Prev Med 2014;69: 80-6.

67. Learnihan V, Van Niel KP, Giles-Corti B, et al. Effect of scale on the links between walking and urban design. Geogr Res 2011;49:183-91.

68. Oliver LN, Schuurman N, Hall AW. Comparing circular and network buffers to examine the influence of land use on walking for leisure and errands. Int J Health Geogr 2007;6:41.

69. The World Bank Group. Data: motor vehicles (per 1,000 people). World Development Indicators, International Road Federation, World Road Statistics and Data Files. 2008; 2015 (February 17)

70. Wasfi RA, Ross NA, El-Geneidy AM. Achieving recommended daily physical activity levels through commuting by public transportation: unpacking individual and contextual influences. Health Place 2013;23:18-25.

71. Jack E, McCormack GR. The associations between objectivelydetermined and self-reported urban form characteristics and neighborhood-based walking in adults. Int J Behav Nutr Phys Act 2014;11:71

72. Van Holle V, Van Cauwenberg J, Van Dyck D, et al. Relationship between neighborhood walkability and older adults' physical activity: results from the Belgian Environmental Physical Activity Study in Seniors (BEPAS Seniors). Int J Behav Nutr Phys Act 2014;11:110.

73. Hirsch JA, Moore KA, Evenson KR, et al. Walk Score(R) and Transit Score $(\mathrm{R})$ and walking in the multi-ethnic study of atherosclerosis. Am J Prev Med 2013;45:158-66.

74. Norman GJ, Carlson JA, O'Mara S, et al. Neighborhood preference, walkability and walking in overweight/obese men. Am J Health Behav 2013;37:277-82.

75. Zander A, Rissel C, Rogers K, et al. Active travel to work in NSW: trends over time and the effect of social advantage. Health Promot $J$ Austr 2014;25:167-73.

76. McCormack GR, Shiell A. In search of causality: a systematic review of the relationship between the built environment and physical activity among adults. Int J Behav Nutr Phys Act 2011;8:125.

77. Boone-Heinonen J, Gordon-Larsen P, Guilkey DK, et al. Environment and physical activity dynamics: the role of residential self-selection. Psychol Sport Exerc 2011;12:54-60.

78. Troped PJ, Wilson JS, Matthews CE, et al. The built environment and location-based physical activity. Am J Prev Med 2010;38:429-38.

79. Rodriguez DA, Brown AL, Troped PJ. Portable global positioning units to complement accelerometry-based physical activity monitors. Med Sci Sports Exerc 2005;37(11 Suppl):S572-81. 